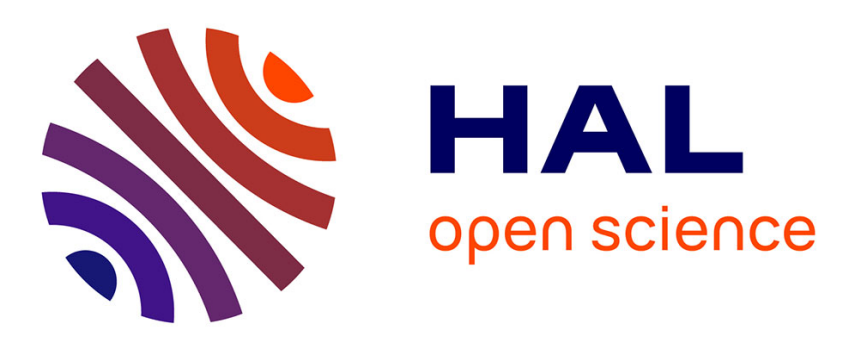

\title{
Synthesis of alternating metallocopolymers by chiral recognition
}

\author{
Maria Torres-werlé, Benoît Heinrich, Aline Maisse-françois, Stéphane \\ Bellemin-laponnaz
}

\section{- To cite this version:}

Maria Torres-werlé, Benoît Heinrich, Aline Maisse-françois, Stéphane Bellemin-laponnaz. Synthesis of alternating metallocopolymers by chiral recognition. Chirality, In press, 31 (11), pp.903-909. 10.1002/chir.23128 . hal-02330384

\section{HAL Id: hal-02330384 https://hal.science/hal-02330384}

Submitted on 23 Oct 2019

HAL is a multi-disciplinary open access archive for the deposit and dissemination of scientific research documents, whether they are published or not. The documents may come from teaching and research institutions in France or abroad, or from public or private research centers.
L'archive ouverte pluridisciplinaire HAL, est destinée au dépôt et à la diffusion de documents scientifiques de niveau recherche, publiés ou non, émanant des établissements d'enseignement et de recherche français ou étrangers, des laboratoires publics ou privés. 


\title{
Synthesis of alternating metallo-copolymers by chiral recognition
}

\author{
Maria Torres-Werlé, ${ }^{[a]}$ Benoît Heinrich, ${ }^{[a]}$ Aline Maisse-François ${ }^{[a]}$ and Stéphane Bellemin- \\ Laponnaz ${ }^{*[a]}$
}

Abstract: We report the synthesis of chiral enantiopure polytopic bridging ligands which may lead to the formation of metallosupramolecular polymers with zinc(II) as metal linker. We show that chiral $C_{2}$-symmetric bisoxazoline ligands are useful moieties to efficiently generate heterochiral complexes and thus polymeric entities. The corresponding metallopolymers were further characterized by powder X-ray diffraction (PXRD) to obtain information on the level of crystallinity of our different metallopolymers.

Keywords: chiral bisoxazoline, polytopic ligand, zinc, metallopolymer

\section{Introduction}

Metallo-supramolecular polymers that combine metal ions and polytopic ligands enable constructing unprecedented materials with specific properties and functions that are of interest for fundamental research but also for the development of new technologies. ${ }^{1,2}$ Indeed, the combination of metal ions with polytopic -organic- ligands necessarily imports the properties of the two components (organic and inorganic) into the final polymer as well as additional properties generated by the metal-ligand coordination such as luminescence for example. These metallopolymers are obtained in a straightforward manner by a process of self-assembly of metal ions with a monomer having linked units (i.e. polytopic ligands) and the resulting polymer may exhibit reversible polymerization I depolymerization characteristics due to the strength of the coordinate interactions. ${ }^{3-7}$

We have recently shown that while most of these polymers consist of a single binding motif, it may be possible to generate alternating metallopolymers with, for example, two different ligands by means of a chiral molecular instruction. ${ }^{8-10}$ The welldefined construction of such copolymers has been possible through heteroleptic coordination under chirality control at the metal center, which contains freely exchangeable ligands under thermodynamic control.

We used the complementarity of these bisoxazoline ligands to generate here alternating metallo-copolymers. Therefore, ditopic, tritopic and tetratopic chiral ligands have been synthesized for that purpose and then used to generate metallopolymers. In all cases, the metallopolymers were instantaneously formed upon addition of zinc salt to a mixture of two ligands of opposite configuration. The resulting solids were characterized including powder $\mathrm{X}$-ray diffraction studies.

\section{Materials and Methods}

\subsection{Chemicals and instruments}

All manipulations were performed under an inert atmosphere of argon or nitrogen using standard Schlenk line techniques. Valinol was obtained by reduction of valine. ${ }^{11} 1,1$-bis[(4S)-4isopropyl-4,5-dihydrooxazol-2-yl]ethane (1) was synthesized according to previous report. ${ }^{12,13}$ Solvents were purified and degassed by standard procedures. All other reagents were commercially available and used as received. Metallopolymers were obtained using methanol as solvent (ACS reagent grade). ${ }^{1} \mathrm{H}$ and ${ }^{13} \mathrm{C}$ Nuclear Magnetic Resonance (NMR) spectra were recorded on a Bruker AVANCE 300 spectrometer using the residual solvent peak as reference $\left(\mathrm{CDCl}_{3}\right.$ : $\delta_{\mathrm{H}}=7.26 \mathrm{ppm} ; \delta_{\mathrm{c}}=$ $77.16 \mathrm{ppm})$ at $298 \mathrm{~K}$. Chemical shifts are given in ppm (ठ) compared to TMS (tetramethylsilane). Infrared (IR) spectra were recorded on a Nicolet $380 \mathrm{FT}-\mathrm{IR}$ spectrometer. $\mathrm{KBr}$ discs were made for all samples. Elemental analyses were recorded by the 'Institut de Chimie' laboratory, Université de Strasbourg. HRMS ESI analyses were recorded on microTOF, Bruker Daltonics by the 'Institut de Chimie' laboratory, Université de Strasbourg. Specific rotations were recorded at the 'Laboratoire de Stéréochimie', ECPM, Strasbourg. The XRD patterns were obtained with a linear monochromatic $\mathrm{Cu}-\mathrm{Ka} 1$ beam $(\lambda=1.5405$ $\AA$ ) by using a sealed-tube generator $(600 \mathrm{~W})$ equipped with a bent quartz monochromator and recorded with a curved Inel CPS120 counter gas-filled detector linked to a data acquisition computer. Periodicities up to $70 \AA$ can be measured, and the sample temperature controlled to within $\pm 0.01{ }^{\circ} \mathrm{C}$ from 20 to $200{ }^{\circ} \mathrm{C}$. In all cases, the crude powder was filled in Lindemann capillaries of $1 \mathrm{~mm}$ diameter and $10 \mu \mathrm{m}$ wall-thickness.

\subsection{Synthesis of polytopic bisoxazolines}

\subsection{1 (S)-iPr-DiBox (2). General procedure. ${ }^{14}$}

1,1'-Bis[(4S)-4,5-dihydro-4-isopropyloxazol-2-yl]ethane (1, 3.96 $\mathrm{mmol}, 1 \mathrm{~g}$ ) was dissolved in dry tetrahydrofuran $(25 \mathrm{~mL})$. A solution of $1.6 \mathrm{M} \mathrm{nBuLi}$ in hexane $(4.31 \mathrm{mmol}, 2.7 \mathrm{~mL})$ was

[a] $\operatorname{Dr}$ M. Torres-Werlé, Dr B. Heinrich, Dr Maisse-François, Dr Bellemin-Laponnaz

Institut de Physique et Chimie de Strasbourg

CNRS - Université de Strasbourg

23, rue du Loess, 67034 STRASBOURG cedex, France Fax: $(+)+33(0) 388107246$

E-mail: bellemin@unistra.fr Published online: ((will be filled in by the editorial staff)) 
added dropwise at $-78{ }^{\circ} \mathrm{C}$. After stirring for $15 \mathrm{~min}$, the bath was removed and $\alpha, \alpha^{\prime}$-dibromo-p-xylene $(1.96 \mathrm{mmol}, 518 \mathrm{mg}$ ) was added. The mixture was then stirred at room temperature for 12 h. The resulting mixture was washed with a saturated $\mathrm{NH}_{4} \mathrm{Cl}$ solution and the aqueous phase was extracted with dichloromethane. The combined organic phases were dried over $\mathrm{Na}_{2} \mathrm{SO}_{4}$. Evaporation of the solvent gave a colourless oil, which was purified by silica gel column chromatography $(\mathrm{AcOEt} / \mathrm{MeOH}$, 95/5) yielding a colourless viscous oil $(1.56 \mathrm{mmol}, 948 \mathrm{mg}$, $80 \%$ ). [a] ${ }_{\mathrm{D}}^{25}:-0.81$ (c $\left.0.5, \mathrm{CHCl}_{3}\right) .{ }^{1} \mathrm{H}$ NMR $\left(300 \mathrm{MHz}, \mathrm{CDCl}_{3}\right): \delta$ $(\mathrm{ppm})=7.03\left(\mathrm{~s}, 4 \mathrm{H} ; \mathrm{H}_{\text {arom}}\right), 4.22\left(\mathrm{dt},{ }^{3} \mathrm{~J}=8.0 \mathrm{~Hz},{ }^{3} \mathrm{~J}=1.3 \mathrm{~Hz}, 4 \mathrm{H}\right.$; $\mathrm{NCH})$, 4.05-3.90 (m, 8H; - $\left.\mathrm{OCH}_{2}\right), 3.24\left(\mathrm{~s}, 4 \mathrm{H} ;-\mathrm{CH}_{2}\right), 1.84-1.67$ (m, 4H; - $\left.\mathrm{CH}\left(\mathrm{CH}_{3}\right)_{2}\right), 1.40\left(\mathrm{~s}, 6 \mathrm{H} ;-\mathrm{C}\left(\mathrm{CH}_{3}\right), 0.94-0.80(\mathrm{~m}, 24 \mathrm{H}\right.$; $\mathrm{CH}\left(\mathrm{CH}_{3}\right) ;{ }^{13} \mathrm{C}\left\{{ }^{1} \mathrm{H}\right\}$ NMR $\left(300 \mathrm{MHz}, \mathrm{CDCl}_{3}\right): \delta(\mathrm{ppm})=167.6$ $(\mathrm{N}=\mathrm{CO}), 134.9\left(-\mathrm{C}_{\text {arom }}\right), 130.1$ (-Carom), 72.0, $71.6(-\mathrm{NCH}), 70.1$, $69.8\left(-\mathrm{OCH}_{2}\right), 43.3\left(-\mathrm{CCH}_{3}\right), 41.8\left(-\mathrm{CH}_{2}\right), 32.5,32.2\left(-\mathrm{CH}\left(\mathrm{CH}_{3}\right)_{2}\right)$, $21.2\left(-\mathrm{C}\left(\mathrm{CH}_{3}\right), 18.8,18.7,17.9,17.5\left(-\mathrm{CH}\left(\mathrm{CH}_{3}\right)_{2}\right)\right.$; IR $(\mathrm{KBr}): \tilde{v}=$ $1658 \mathrm{~cm}^{-1}(\mathrm{~s}, \mathrm{C}=\mathrm{N})$; MS (ESI +$): \mathrm{m} / \mathrm{z}: 607.42[\mathrm{M}+\mathrm{H}]^{+}$; elemental analysis calcd (\%) for $\mathrm{C}_{36} \mathrm{H}_{54} \mathrm{~N}_{4} \mathrm{O}_{4}$ : C 71.25, H 8.97, N 9.23; found $\mathrm{C} 70.97, \mathrm{H}$ 8.89, N 9.21. (R)-iPr-DiBox was obtained using the same procedure from 1,1'-Bis[(4R)-4,5-dihydro-4isopropyloxazol-2-yl]ethane.

\subsection{2 (S)-iPr-BP-DiBox (3)}

The general procedure was followed: $2.00 \mathrm{mmol}(51 \%$ yield). $[\alpha]_{\mathrm{D}}{ }^{25}:-0.59 .{ }^{1} \mathrm{H}$ NMR $\left(300 \mathrm{MHz}, \mathrm{CDCl}_{3}\right): \delta(\mathrm{ppm})=7.42(\mathrm{~d}, \mathrm{~J}=$ $8.2 \mathrm{~Hz}, 4 \mathrm{H}$; Harom), 7.21 (d, J= 8.3 Hz, 4H; Harom), 4.30-4.23 (m, $4 \mathrm{H}$; $-\mathrm{NCH}), 4.07-3.91\left(\mathrm{~m}, 8 \mathrm{H} ;-\mathrm{OCH}_{2}\right), 3.33(\mathrm{q}, \mathrm{J}=13.5 \mathrm{~Hz}, 4 \mathrm{H}$; $\left.\mathrm{CH}_{2}\right), 1.85-1.73\left(\mathrm{~m}, 4 \mathrm{H} ;-\mathrm{CH}\left(\mathrm{CH}_{3}\right)_{2}\right), 1.47\left(\mathrm{~s}, 6 \mathrm{H} ;-\mathrm{C}\left(\mathrm{CH}_{3}\right), 0.95-\right.$ $0.81\left(\mathrm{~m}, 24 \mathrm{H} ;-\mathrm{CH}\left(\mathrm{CH}_{3}\right)_{2} ;{ }^{13} \mathrm{C}\{1 \mathrm{H}\} \mathrm{NMR}\left(300 \mathrm{MHz}, \mathrm{CDCl}_{3}\right): \delta\right.$ $(\mathrm{ppm})=167.5(\mathrm{~N}=\mathrm{CO}), 139.5\left(-\mathrm{C}_{\text {arom }}\right), 135.6\left(-\mathrm{C}_{\text {arom }}\right), 130.8(-$ Carom), 126.6 (-Carom), 72.0, $71.6(-\mathrm{NCH}), 70.1,69.8\left(-\mathrm{OCH}_{2}\right)$, $43.4\left(-\mathrm{CCH}_{3}\right), 41.8\left(-\mathrm{CH}_{2}\right), 32.4,32.3\left(-\mathrm{CH}\left(\mathrm{CH}_{3}\right)_{2}\right), 21.3(-$ $\mathrm{C}\left(\mathrm{CH}_{3}\right), 18.8,18.7,17.9,17.5\left(-\mathrm{CH}\left(\mathrm{CH}_{3}\right)_{2}\right) ; \mathrm{IR}(\mathrm{KBr}): \tilde{\mathrm{v}}=1655$ $\mathrm{cm}-1$ (s, C=N); MS (ESI +): m/z (\%): $684.45[\mathrm{M}+\mathrm{H}]^{+}$; elemental analysis calcd (\%) for $\mathrm{C}_{42} \mathrm{H}_{58} \mathrm{~N}_{4} \mathrm{O}_{4}$ (682.93): C 73.86, $\mathrm{H}$ 8.56, $\mathrm{N}$ 8.20; found $\mathrm{C} 73.94, \mathrm{H} 8.60, \mathrm{~N}$ 8.02. (R)-iPr-BP-DiBox was obtained using the same procedure starting from 1,1'-Bis[(4R)4,5-dihydro-4-isopropyloxazol-2-yl]ethane.

\subsection{3 (S)-iPr-TriBox (4)}

The general procedure was followed to give the product with identical analytical data as already reported by us. ${ }^{14}$

\subsection{4 (S)-iPr-TetraBox (5)}

The general procedure was followed to give the product with identical analytical data as already reported by us. ${ }^{14}$

\subsection{Synthesis of metallopolymers.}

\subsubsection{Metallopolymer (6) $[\mathrm{Zn}+(R)-\mathrm{iPr}-\mathrm{DiBox}+(S)$-iPr-DiBox $]$. General procedure.}

Ligands $(R)-(2)(R)-\mathrm{iPr}$-DiBox and $(S)-(2)(S)-\mathrm{iPr}-\mathrm{DiBox} \quad(0.12$ $\mathrm{mmol}, 75 \mathrm{mg}$ each) were dissolved in methanol $(1.0 \mathrm{~mL})$. The resulting colorless solution was stirred for 10 minutes before adding dropwise solution of $\mathrm{Zn}\left(\mathrm{BF}_{4}\right)_{2}(0.24 \mathrm{mmol}, 57 \mathrm{mg})$ in methanol $(1.0 \mathrm{~mL})$. The mixture led to the instantaneous formation of an opaque gel. The polymer was then isolated by addition of diethyl ether followed by filtration, giving a white powder in quantitative yield. IR $(\mathrm{KBr}): \tilde{\mathrm{v}}=1634 \mathrm{~cm}-1(\mathrm{~s}, \mathrm{C}=\mathrm{N})$; elemental analysis calcd (\%) for $\mathrm{C}_{72} \mathrm{H}_{108} \mathrm{~B}_{4} \mathrm{~F}_{16} \mathrm{~N}_{8} \mathrm{O}_{8} \mathrm{Zn}_{2}$ : C 51.12 , H 6.43, N 6.62; found C 51.53, H 6.68, N 6.75. Since the product is insoluble in most common solvents, the NMR spectrum could not be taken. Thermo-Gravimetric Analysis (TGA) revealed that the decomposition of the samples occurs above $200{ }^{\circ} \mathrm{C}$, without crossing any phase transition.

\subsubsection{Metallopolymer (7) $[\mathrm{Zn}+(\mathrm{S})$-iPr-BP-DiBox $+(R)$-iPr-BP- DiBox]}

The general procedure was followed $(0.25 \mathrm{mmol}$ of $\mathrm{Zn}$, quantitative yield). Since the product is insoluble in most common solvents, the NMR spectrum could not be taken. Elemental analysis calcd (\%) for $\mathrm{C}_{84} \mathrm{H}_{116} \mathrm{~B}_{4} \mathrm{~F}_{16} \mathrm{~N}_{8} \mathrm{O}_{8} \mathrm{Zn}_{2}$ : C 54.72, H 6.34, N 6.06; found C 54.29, H 6.43, N 5.87.

\subsubsection{Metallopolymer (8) $[\mathrm{Zn}+(S)$-iPr-DiBox $+(R)$-iPr-BP- DiBox]}

The general procedure was followed $(0.25 \mathrm{mmol}$ of $\mathrm{Zn}$, quantitative yield). ${ }^{1} \mathrm{H}$ NMR $\left(300 \mathrm{MHz}, \mathrm{CD}_{3} \mathrm{OD}\right): \delta(\mathrm{ppm})=7.51$ (d, Jortho $=8.2 \mathrm{~Hz}, 4 \mathrm{H}$; Harom), 7.25 (d, Jortho $=7.9 \mathrm{~Hz}, 4 \mathrm{H}$; Harom) 7.10 (bs, $4 \mathrm{H}, \mathrm{H}_{\text {arom }}$ ), 4.39-3.94 (m, 24H), 1.86-1.71 (m, 20H), 0.94-0.85 $(\mathrm{m}, 48 \mathrm{H})$. Elemental analysis calcd (\%) for $\mathrm{C}_{78} \mathrm{H}_{112} \mathrm{~B}_{4} \mathrm{~F}_{16} \mathrm{~N}_{8} \mathrm{O}_{8} \mathrm{Zn}_{2}$ : C 52.48, H 6.41, N 6.30; found C 52.06, H 6.73, N 6.29.

\subsubsection{Metallopolymer (9) $[\mathrm{Zn}+(R)-\mathrm{iPr}-\mathrm{DiBox}+(\mathrm{S})$-iPr-TriBox $]$}

The general procedure was followed $(0.25 \mathrm{mmol}$ of $\mathrm{Zn}$, quantitative yield). ${ }^{1} \mathrm{H}$ NMR $\left(300 \mathrm{MHz}, \mathrm{CD}_{3} \mathrm{OD}\right): \delta(\mathrm{ppm})=7.14-$ $6.99(\mathrm{~m}, 7 \mathrm{H}, \mathrm{H}$ arom $), 4.40-3.35(\mathrm{~m}, 30 \mathrm{H}), 2.98-2.92(\mathrm{~m}, 10 \mathrm{H})$, 1.96-1.29 $(\mathrm{m}, 25 \mathrm{H}), 0.93-0.85(\mathrm{~m}, 60 \mathrm{H})$. Elemental analysis calcd (\%) for $\mathrm{C}_{210} \mathrm{H}_{318} \mathrm{~B}_{12} \mathrm{~F}_{48} \mathrm{~N}_{24} \mathrm{O}_{24} \mathrm{Zn}_{6}$ : C 50.48, H 6.41, N 6.73; found C 50.84, H 6.88, N 6.62.

\subsubsection{Metallopolymer (10) $[\mathrm{Zn}+(R)$-iPr-DiBox $+(S)$-iPr- TetraBox]}

The general procedure was followed $(0.25 \mathrm{mmol}$ of $\mathrm{Zn}$, quantitative yield). ${ }^{1} \mathrm{H}$ NMR (300 $\left.\mathrm{MHz}, \mathrm{CD}_{3} \mathrm{OD}\right): \delta=7.13-6.99$ $\left(\mathrm{m}, 6 \mathrm{H}, \mathrm{H}_{\text {arom }}\right), 4.87-3.54(\mathrm{~m}, 36 \mathrm{H}), 2.98-2.92(\mathrm{~m}, 10 \mathrm{H}), 1.98-$ $1.24(\mathrm{~m}, 30 \mathrm{H}), 0.96-0.85(\mathrm{~m}, 72 \mathrm{H})$. Elemental analysis calcd $(\%)$ for $\mathrm{C}_{138} \mathrm{H}_{210} \mathrm{~B}_{8} \mathrm{~F}_{32} \mathrm{~N}_{16} \mathrm{O}_{16} \mathrm{Zn}_{4}$ : C $50.15, \mathrm{H} 6.40, \mathrm{~N} 6.78$; found $\mathrm{C}$ 50.85, H 6.79, N 6.63.

\section{Results and Discussion}

The chiral ligands were synthesized according to the general scheme described in Figure 1. They were obtained in one step from methyl-bis(oxazolinyl)methane derivative ${ }^{15}$ by deprotonation with $\mathrm{n}-\mathrm{BuLi}$ followed by reaction with the appropriate electrophile (i.e., $\alpha, \alpha^{\prime}$-dibromo- $p$-xylene, $\alpha, \alpha^{\prime}$ dibromo- $p, p^{\prime}$-bitolyl, 1,3,5-tris (bromomethyl)-benzene or 1,2,4,5- 
tetrakis (bromomethyl)-benzene). ${ }^{16,17}$ All compounds were characterized by classical analytical methods. For the purpose of our studies both enantiomers of ditopic ligand (2) and (3) were synthesized whereas ligand (4) and (5) were synthesized starting from $(S)$ valinol.

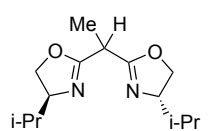

(1)

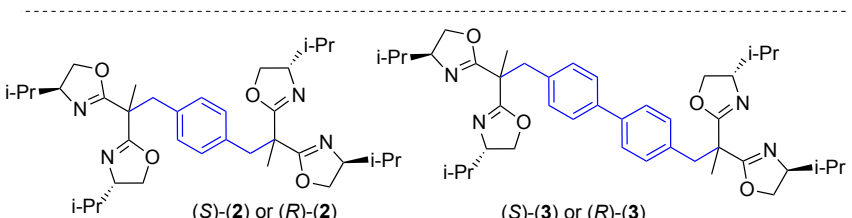

$(S)-(2)$ or $(R)-(2)$
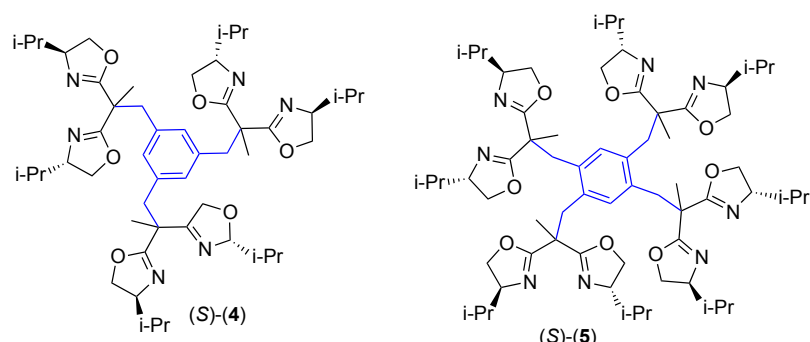

FIGURE 1 Synthesis of polytopic ligands in enantiomeric form from (S)-(1) or (R)-(1). Conditions: 1) n-BuLi, $-78{ }^{\circ} \mathrm{C}, 15 \mathrm{~min}$ in THF; 2) Electrophile (0.5, 0.33 or 0.25 equiv.), R.T. $12 \mathrm{~h}$.

On the basis of chiral molecular assemblies, the successful construction of an alternate metallo-copolymer is only possible by formation of heterochiral complexes, which has been shown to be possible using $C_{2}$-symmetric bisoxazoline ligands. Indeed, the least sterically hindered [ML2]-type complex in a tetrahedral environment combines two chiral $C_{2}$-symmetric bisoxazoline ligands of opposite sign, as displayed in Figure 2.8,9 This strategy allowed us to construct several metallopolymers with ditopic ligands. We then decided to extend this strategy to synthesize various metallopolymers in particular using units with higher topicity.
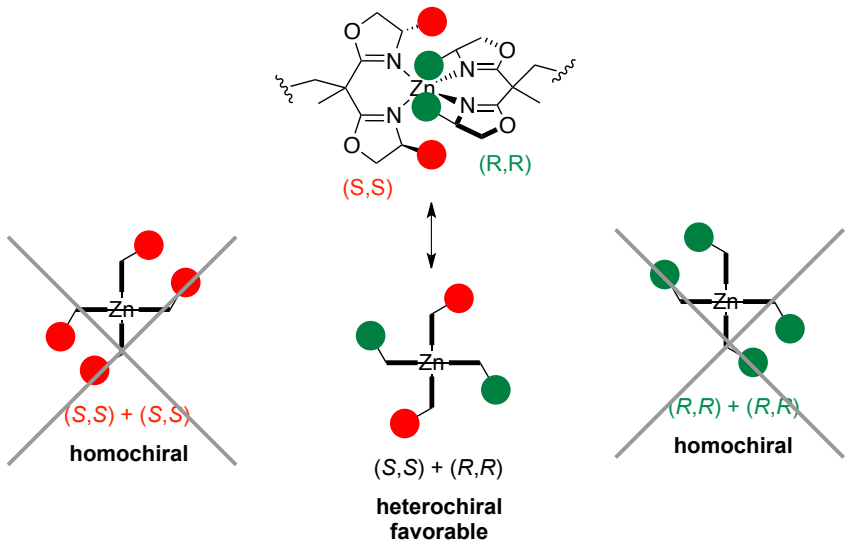

heterochiral
favorable

FIGURE 2 Shaping coordination spheres with chiral $C_{2}$-symmetric bisoxazoline derivatives: favorable combination in $\left[\mathrm{Zn}(\mathrm{bisox})_{2}\right]^{2+}$ complexes in a tetrahedral environment, demonstrating the complementarity of opposite enantiomers.

Using ligands (2) to (5), we synthesized five different zinc-based metallopolymers as shown in Figure 3 . In all cases, they were instantaneously formed upon addition of $\mathrm{Zn}\left(\mathrm{BF}_{4}\right)_{2}$ to a methanol solution containing two ligands of opposite configuration and in the appropriate stoichiometric proportion. Metallopolymers (6) and (7) were generated from the racemic iPr-DiBox ligand (2) and $\mathrm{iPr}-\mathrm{BP}-\mathrm{DiBox}$ ligand (3), respectively. Metallopolymer (8) was obtained from the iPr-DiBox ligand $(R)-(2)$ and iPr-BP-DiBox ligand $(S)-(3)$, whereas metallopolymers (9) and (10) were obtained by combination of $(R)-(2)$ with the tritopic ligand $(S)-(4)$ or the tetratopic ligand (S)-(5), respectively. In all cases, a white gel-like material was spontaneously formed upon addition of the zinc precursor. All polymers have then been isolated as white solids in close-to-quantitative yield by addition of diethylether and elemental analyses confirmed the purity of the products. Interestingly, all attempts to generate metallopolymers using ligands with the same absolute configuration were unsuccessful thus confirming the need of heterocomplementarity to form the metal complexes. Figure 4 displays the methanol solution containing equimolar amount of ligand $(R)-(2)$ and $(S)-(3)$ prior to addition to the metal salt (a) and after addition (b) showing the formation of the polymer (8). Figure 4 (c) displays the ${ }^{1} \mathrm{H}$ NMR spectra of the resulting polymer that has been isolated by precipitation with diethylether and filtration. Integration of the signals confirmed the stoichiometric composition of resulting metallo-polymer.

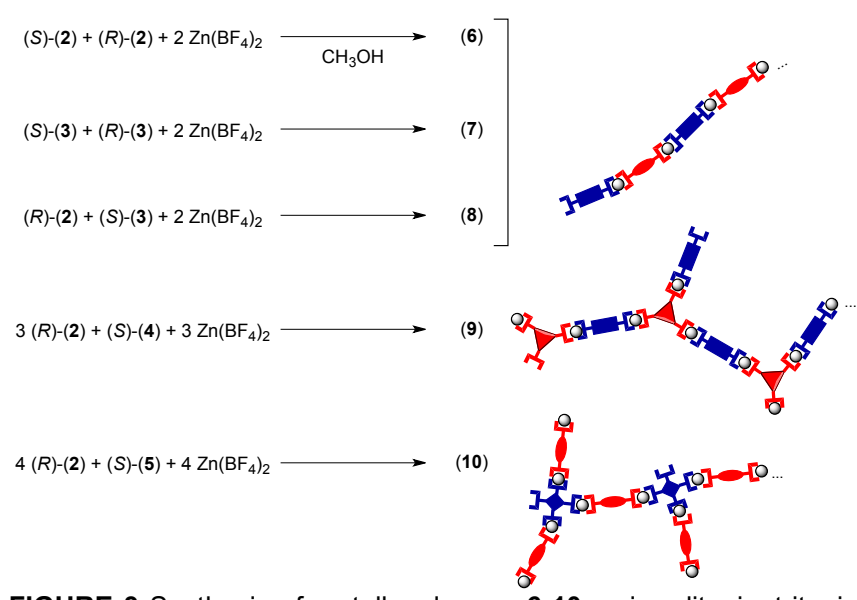

FIGURE 3 Synthesis of metallopolymers 6-10, using ditopic, tritopic or tetratopic ligands (2-5). Conditions: $\mathrm{MeOH}$ at room temperature.
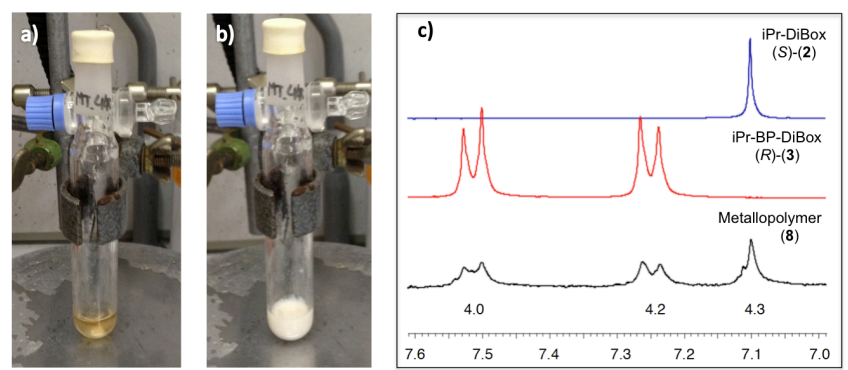

FIGURE 4 Pictures of the resulting solution before (a) and after (b) complexation of $\mathrm{Zn}\left(\mathrm{BF}_{4}\right)_{2}$ with an equimolar amount of $(R)-(2)$ and $(S)$-(3); c) ${ }^{1} \mathrm{H}$ NMR spectra $\left(\mathrm{CD}_{3} \mathrm{OD}\right.$, aromatic region) of $(S)$-iPrDiBox (top), (R)-iPr-BP-DiBox (middle) and the corresponding copolymer (bottom) obtained from $\mathrm{Zn}\left(\mathrm{BF}_{4}\right)_{2}$.

We then studied our Zn (II) compounds by powder X-ray diffraction (PXRD), to obtain information on the level of crystallinity of our different products. In the case of the metallopolymer (6), the structure turned out to be semicrystalline with nanometer-size crystals leading to broadened reflections, as displayed in Figure 5. 


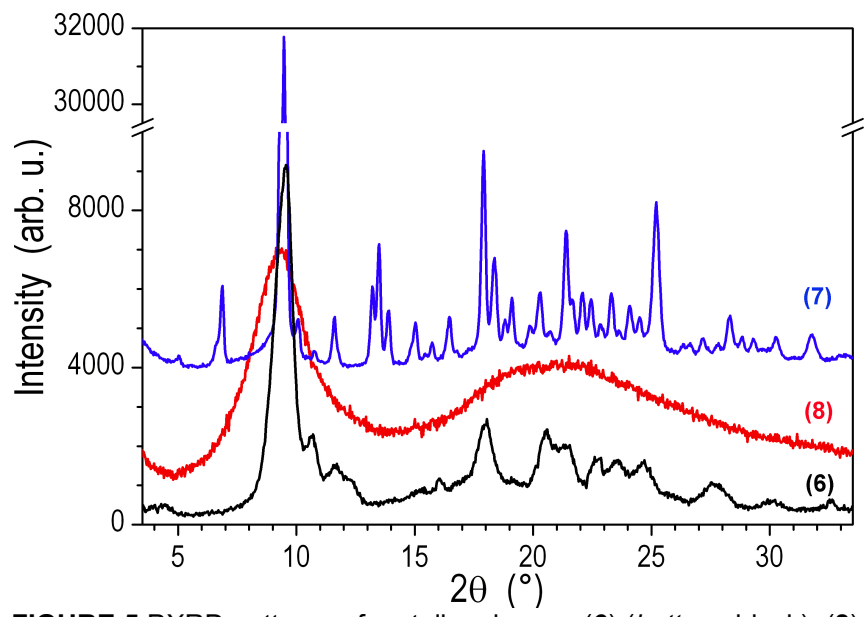

FIGURE 5 PXRD patterns of metallopolymers (6) (bottom, black), (8) (middle, red) and (7) (top, blue).

Although the overlapping and the poorly defined positions of the reflections precludes the resolution of the average crystalline structure, the information from PXRD pattern is sufficient for a general description of the material state. Specifically, the main diffracted intensity shares in two groups of unresolved reflections: one at small-angles (around the major peak at $9.5^{\circ}$ corresponding to $9.3 \AA$ ) from the lateral arrangement of polymer chains and counter-ions, and a group at wide-angles $\left(18-25^{\circ}\right.$ corresponding to 5-3.5 $\AA$ ) from periodicities in the range of lateral distances between close-packed molecular segments. Outside these groups, diffracted signals are essentially blurred out by the structural disorder, whereupon the molecular organization could be considered as "soft-crystalline", as meaning in a state intermediate between crystalline and amorphous solids. For metallopolymer (8), also shown in figure 5 , crystallinity even totally vanished since the patterns only contains two broad scattering signals from average lateral distances between polymer chains and molecular segments. The similarity of their shapes and positions with those of the unresolved reflection groups of (6) strongly suggests close localrange arrangements for both polymers. They indeed contain the same metal ion and counter-ions, whose arrangement into ionic strata drives the self-assembly. The nature of the organic spacers and their sequence in the backbones allows however to modulate the emerging structure or here to obtain such a structure only for (6). The reason is obviously that (6) exclusively associates enantiomeric units of type (2), while (8) alternates type (2) and type (3) units: complexes from successive strata are hence connected by a phenyl spacer in (6), while they are either connected by a phenyl or a longer biphenyl spacer in (8). Prerequisite for crystallization in this latter case is that polymers self-assemble in a way that all spacers of same nature locate on the same side of ionic strata. Such an unlikely configuration is perhaps not possible for (8), which would then explain that this polymer stays in an amorphous-like state. Confirmation of this view is brought by polymer (7) in figure 5 , for which both (2) units were replaced by (3), and thus all phenyl spacers by biphenyl. Constrain from spacer location was therefore removed and crystallization effectively reappeared. Ionic parts being identical for (6) and (7), structures are also quite similar, with in particular the same major periodicity at $9.3 \AA$ from the lateral arrangement of polymers. There is nevertheless a striking difference in the regularity and correlation length of the structures: for (7), reflections are substantially sharper and appear in the whole scattering range; this material is hence in a fine-powdered crystalline state. It is unclear why the spacer nature has this effect: tentatively, it could be related to the contribution of biphenyl to close-packing or to the higher spacing of ionic strata. Apart from modulating the emerging structure, the organic spacer offers an easy route toward higher topicity and up to 4 coordinating sites could be introduced on phenyl and combined to ditopic ligands, to yield the metallocopolymers (9) and (10), whose PXRD patterns are displayed in Figure 6. It was expected that ramifications would perturb the close-packing, and effectively crystallinity vanished for both copolymers. The patterns of these amorphous-like polymers display the two scattering signals from the local-range close-packing of entire polymers and molecular segments. The shapes and positions of these signals stay similar to those of the unresolved reflection groups of the linear polymer (6), indicating that ramifications have little impact on the local-range packing of complexes and counter-ions.

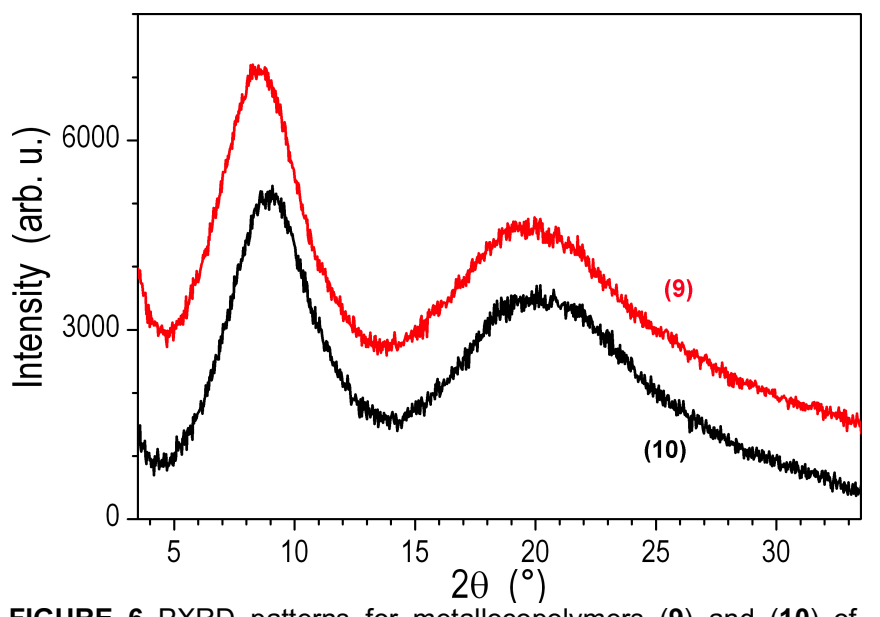

FIGURE 6 PXRD patterns for metallocopolymers (9) and (10) of topicity higher than 2 .

\section{Conclusion}

In conclusion, we have shown that using zinc ions alternate metallocopolymers may be easily produced through the formation of heterochiral [ML2]-type complexes. Indeed, chiral $C_{2}$-symmetric bisoxazoline derivatives exhibit the good spatial arrangement to generate these heterochiral species. When ditopic ligands of opposite configuration were used such as $(S)$ $(2)$ and $(R)-(2)$ or $(S)-(3)$ and $(R)-(3)$, semi-crystalline solids were obtained. Other combination led to amorphous solids, such as pairing of $(S)-(2)$ with $(R)-(3)$ for example. In addition, ligands of higher topicity also led to amorphous materials. Indeed, ramifications may perturb the close-packing and crystallinity disappears as soon as topicity of the ligand is higher than 2 . From these experiments we can further conclude that prerequisite for crystallization of linear metallopolymers from ditopic ligands is that they self-assemble in a way that all spacers of same nature locate on the same side of ionic strata.

\section{Acknowledgements}

This work was funded by the French National Research Agency (ANR) through the Programme d'Investissement d'Avenir under contract ANR-11-LABX-0058_NIE within the Investissement d'Avenir program ANR-10-IDEX-0002-02. 


\section{REFERENCES AND NOTES}

1. Whittel GR, Hager MD, Schubert US, Manners I. Functional soft materials from metallopolymers and metallosupramolecular polymers. Nature Materials 2011;10(3):176-188.

2. Wojtecki RJ, Meador MA, Rowan SJ, Using the dynamic bond to access macroscopically responsive structurally dynamic polymers. Nature Materials 2011;10(1):14-27.

3. Friese VA, Kurth DG, From coordination complexes to coordination polymers through self-assembly. Curr. Opin. Colloid Interface Sci. 2009;14(2):81-93.

4. Lehn JM, Dynamers: Dynamic Molecular and Supramolecular Polymers. Aus. J. Chem., 2010;63(4):611-623.

5. Yang L, Tan X, Wang Z, Zhang X, Supramolecular Polymers: Historical Development, Preparation, Characterization, and Functions. Chem. Rev. 2015, 115(15):7196-7239.

6. Winter A, Schubert US, Synthesis and characterization of metallo-supramolecular polymers. Chem. Soc. Rev. 2016, 45:5311-5357.

7. Lehn, JM, Dynamers: dynamic molecular and supramolecular polymers. Prog. Polym. Sci. 2005, 30:814-831.

8. Torres $M$, Heinrich B, Miqueu K, Bellemin-Laponnaz S. Chirality-Driven Metallo-Copolymer Formation. Eur. J. Inorg. Chem. 2012:3384-3387.

9. Marinova M, Torres-Werlé M, Taupier G, Maisse-François A, Achard T, Boeglin A, Dorkenoo KDH, Bellemin-Laponnaz S. Chiral Self-Sorting Process with Ditopic Ligands: Alternate or Block Metallopolymer Assembly as a Function of the Metal Ion. ACS Omega 2019, 4:2676-2683.

10. Taupier G, Torres-Werlé M, Boeglin A, Maisse-François A, Achard T, Bellemin-Laponnaz S, Dorkenoo HD. Optically
Active Sum-Frequency Generation as an Advanced Tool for Chiral Metallopolymer Material. Appl. Phys. Lett. 2017, 110:021904.

11. Abiko A, Masamune S. An improved, convenient procedure for reduction of amino acids to aminoalcohols: Use of $\mathrm{NaBH}_{4}-$ $\mathrm{H}_{2} \mathrm{SO}_{4}$. Tetrahedron Lett. 1992, 33(38):5517-5518.

12. Dagorne S, Bellemin-Laponnaz S, Welter R. Synthesis and Structure of neutral and cationic aluminium complexes incorporating bis-oxazolinato ligands. Organometallics 2004, 23(12):3053-3061.

13. Seitz M, Capacchione C, Bellemin-Laponnaz S, Wadepohl $\mathrm{H}$, Ward BD, Gade LH. Bisoxazolines with one and two sidearms: stereodirecting ligands for copper-catalysed asymmetric allylic oxidations of alkenes. Dalton Trans. 2006, (1):193-202.

14. Torres M, Maisse-François A, Bellemin-Laponnaz S. Highly Recyclable Self-Supported Chiral Catalysts for the Enantioselective $\alpha$-Hydrazination of $\beta$-Ketoesters. ChemCatChem 2013, 5(10):3078-3085.

15. For a review on bis(oxazolinate), see: Dagorne $S$, BelleminLaponnaz S, Maisse-François A, Eur. J. Inorg. Chem. 2007, (7):913-925.

16. Nano A, Brelot L, Rogez G, Maisse-François A, BelleminLaponnaz S. Ditopic bis(oxazolines): Synthesis and structural studies of zinc(II), copper(II) and nickel(II) complexes. Inorg. Chem. Acta 2011, 376(1):285-289.

17. Torres-Werlé M, Nano A, Maisse-François A, BelleminLaponnaz S. Asymmetric benzoylation and Henry reaction using reusable polytopic bis(oxazoline) ligands and copper(II). New J. Chem. 2014, 38(10):4748-4753. 